\title{
Pengaruh Pembelajaran Berbasis Masalah Sistem Daring Berbantuan Google Classroom Kombinasi Zoom Terhadap Hasil Belajar Ekonomi Mikro dan Tanggung Jawab Pada Mahasiswa Program Studi Pendidikan Ekonomi Dimasa New Normal
}

\author{
Sulastri Rini Ridrayani \\ Sulastristkippgrita@gmail.com \\ Program Studi Msgister Pendidikan IPS, Universitas Bhinneka PGRI
}

\begin{abstract}
Online learning in all education levels, from elementary school up to university levels is one effect of the outbreak of Covid-19 pandemic. This research was aimed at analyzing the effectiveness of problem based online learning using the combination of google classroom and zoom on students' microeconomics learning outcome and responsibility. The data were collected by using subjective test on students' learning outcome and questionnaire on students' responsibility. Further, the data were analyzed by using One Way Manova, which simultaneously showed that there is a significant difference on Microeconomics 1 learning outcome and responsibility of students who experienced problem based on the online learning using combination of Google Classroom and Zoom, proven by F count of Pillai's Trace Of 66.789 at sig. $0.00<0.05$. In univariate, there is a significant difference on Microeconomics 1 learning outcome of students who experienced problem based online learning using combination of Google Classroom and Zoom, proven by $F$ count of 135.215 at sig. $0.00<0.05$. However, there is no significant difference on responsibility of students who experienced problem based online learning using combination of Google Classroom and Zoom, proven by F count of 0.119 at sig. $0.731>0.05$.
\end{abstract}

Keywords: online learning , learning outcome , responsibility

\begin{abstract}
Abstrak
Pandemi Covid 19 berdampak pada pembelajaran di tingkat sekolah sampai Perguruan Tinggi dilakukan secara daring.Penelitian ini bertujuan menganalisis pengaruh pembelajaran berbasis masalah sistem daring berbantuan google classroom kombinasi zoom terhadap hasil belajar Ekonomi Mikro dan Tanggung Jawab Pada Mahasiswa Program Studi Pendidikan Ekonomi dimasa New Normal. Populasi penelitian adalah Mahasiswa program Studi pendidikan Ekonomi sedang menempuh mata kuliah Ekonomi Mikro 1 sebanyak 84 mahasiswa. .Metode pengumpulan data menggunaka tes subyektif untuk mengumpulkan data hasil belajar dan kuesioner untuk mengumpulkan data Tanggung jawab. Analisis data menggunakan statistik Uji One Way Manova. Hasil Analisis data secara simultan menunjukan ada perbedaan yang segnifikan Pembelajaran berbasis masalah sistem daring berbantuan google classroom kombinasi zoom terhadap hasil belajar Ekonomi Mikro 1 dan tanggung jawab, terbukti nilai $F$ hitung Pillai's Trace sebesar 66.789 pada .sig $0.00<0,05$. Secara univariate ada berbedaan yang signifikan pembelajaran berbasis masalah sistem daring berbantuan google classroom kombinasi zoom terhadap hasil Belajar Ekomo mikro 1 terbukti nilai $F=135.215$ pada sig $0,00<0,05$. Tetapi tidak ada perbedaan pembelajaran berbasis masalah sistem daring berbantuan google classroom kombinasi zoom terhadap tanggung jawab terbukti nilai $F=0.119$ pada sig $0,731>0,05$.
\end{abstract}

Kata Kunci: Pembelajaran daring, hasil belajar, tanggung jawab

\section{PENDAHULUAN}

Adanya covid 19 menuntut semua pendidik dari Sekolah Dasar sampai Perguruan Tinggi pembelajaran dilakukan secara daring. Semua Dosen di Universitas Bhinneka PGRI dalam memberikan kuliah dengan menggunakan sistem daring, kecuali mata kuliah praktik diperbolehkan luring dengan memetahuhi ketentuan protocol kesenhatan. Pembelajaran daring adalah aktifitas belajar-mengajar 


\section{Efektor, Volume 8 Issue 2,2021, Pages 122 - 131 \\ Sulastri Rini Ridrayani}

yang menggunakan internet, intranet, dan ekstranet, atau dapat juga disebut dengan pembelajaran yang menggunakan jaringan komputer yang terhubung secara langsung .(Rusydiyah et al., 2019). Macam-macam platform pembelajaran elektronik yang berbasis media sosial dalam pembelajaran era milenial: Edmodo, Edublog, Google Clasroom,Skype.(Rusydiyah et al., 2019) Berbagai platform pembelajaran elektronik yang digunakan dosen Universitas Bhinneka antara lain Edmodo, Edublog, Google Clasroom, Zoom, dan WatsApp. Penggunaan media pembelajaran berbasis daring pada dasar upaya dari sermua dosen agar capaian pembelajaran mata kuliah dapat tersampaikan dengan baik. Selain itu diharapkan mahasiswa bisa memahami materi dengan baik dan mengerjakan tugas sesuai yang ditentukan.

Ekonomi Mikro merupakan mata kuliah wajibtempuhmahasiswa Program Studi Pendidikan Ekonomi. Mata kuliah ini terdiri dari Ekonomi Mikro 1 mempelajari perilaku konsumen yang diberikan pada Semester 2 dan Ekonomi Mikro 2 mempelajari perilaku produsen diberikan pada semester 3.Mata Kuliah ini harus dikuasai oleh mahasiswa Pendidikan Ekonomi karena mata kuliah ini sebagai bahan untuk magang mengajar mata pelajaran ekonomi tingkat SMA. Namun demikian, dari hasil evaluasi sebagian besar mahasiswa memperoleh nilai rendah karena kesulitan dalam membuat dan menjelaskan grafik tersebut. Hal ini dapat dilihat dari hasil nilai mengerjakan soal subyektif pada soal penawaran, permintaan, elasisitas, dan nilai guna terbukti $55 \%$ menyelesaikan soal benar dan lengkap jawabanya, sedangkan sebanyak $20 \%$ jawaban benar dan belum lengkap, sedangkan sebanyak $25 \%$ salah.

Pembelajaran Ekonomi Mikro sebelum pandemi covid 19 dilakukan dengan metode diskusi, pemberian tugas dan presentasi. Pemberian tugas kelompok untuk dikerjakan di rumah kemudian dipresntasikan. Namun demikian dalam mengerjakan tugas kelompok ini tidak semua ikut menyelesaikan tugas kelompoknya, hal ini terbukti pada kegiatan presentasi mahasiswa yang tidak ikut mengerjakan tidak bisa menjelaskan materi yang dipresentasikan. Kondisi ini juga membuktikan mereka tidak bertanggung jawab atas tugas yang diberikan, artinya tanggung jawab pada mahasiswa masih rendah. Dari hasil penilaian dengan menggunakan metode observasi pelaksanaan diskusi $65 \%$ memiliki tanggung jawab untuk mengerjakan dan mampu mengerjakan tetapi sebanyak 35\% mahasiswa tidak bertanggung jawab mengerjakan dan menjelaskan dengan baik. Kurangnya tanggung jawab ini juga akan berdampak pada kurangnya penguasaan materi dan pada akhirnya rendahnya hasil belajar.

Pada masa new normal covid 19 pembelajaranEkonomi Mikro diberikan Fully Online E-Learning Format artinya keseluruhan kegiatan pembelajaran baik langsung maupun tak langsung secara daring.(Rusydiyah et al., 2019). Untuk meningkangkan hasil belajar dan tanggung jawab pembelajaran ekonomi mikro dilakukan secara daring dengan metode berbasis masalah berbantuan goole classroom dan zoom. Pemilihan metode pembelajaran berbasis masalah sesuai hasil penelitian Santika membuktikan pembelajaran berbasis masalah dalam setting pembelajaran daring terdapat perbedaan prestasi belajar matematika antara siswa yang belajar dengan model pembelajaran berbasis masalah dan model pembelajaran langsung.(Santika, Parwati, \& Divayana, 2020). Pendapat lain Pembelajaran berbasis masalahemfokuskan peserta didik untuk bersikap aktif, tidak hanya pasif memperhatikan pengajaran dari guru. Peserta didik dapat mengemukakan pemikirannya, saling bertukar pendapat, saling bekerja sama jika ada teman dalam kelompok yang mengalami kesulitan.(Julita, 2018). Hasil penelitian Julita menunjukkan bahwa terdapat peningkatan ketuntasan hasil belajar peserta didik dan terdapat peningkatan keaktivan peserta didik dan guru dalam proses problem based- learning.(Julita, 2018). Dari bebnerapa penelitian sebelumnya pembelajaran berbasis masalah dapat meningkatkan hasil belajar dan keaktifan siswa dalam proses belajar.

Pengunaan kombinasi ini dengan tujuan agar pelaksanaan pembelajaran bisa optimal. Sesuai dengan pendapat(Rusydiyah et al., 2019), (Rostyanta, Sutiadiningsih, Bahar, \& Miranti, 2020), (Suhada et al., 2020) bahwa Google Classroom adalah media pembelajaran yang menarik, dapat dimanfaatkan oleh siapa sajadan gratis. Aplikasi ini menyediakan materi, tes, dan penilaian sehingga belajar lebih mudah dan dinamis. Sedangkan aplikasi zoom adalah sebuah aplikasi yang dapat melaksanakan kegiatan 


\section{Efektor, Volume 8 Issue 2,2021, Pages 122 - 131 \\ Sulastri Rini Ridrayani}

meeting atau diskusi pendidik dan peserta didik secara bersama seperti bertatap muka langsung tanpa harus bertemu secara fisik(Fiyanti, Rahmawati, \& Wulandari, 2020). Diperkuat pendapat(Monica \& Fitriawati, 2020)Efektivitas pembelajaran mengunakan Zoom dapat tercapai salah satunya dengan menggunakan media pembelajaran dalam proses pembelajaran yang sesuai dengan situasi dan kondisi, baik dari konten materi ataupun keadaan lingkungan mahasiswa. Penyampaian suatu konsep pada siswa akan tersampaikan denganbaik jika konsep tersebut mengharuskan siswa terlibat langsung didalamnya

Berdasarkan berbagai teori tersebut pembelajaran ekonomi mikro perlu disampaikan dengan sistem daring yang dapat membuat siswa aktif dan terlibat langsung dalam pembelajaran sehingga pembelajaran bermakna. Oleh karenanya sistem daring berbasis masalah merupakan metode yang sesuai dengan media pembelajaran Google Classroom dan Zoom. Google Clasroom digunakan untuk memberikan tugas individu atau kelompok sedangkan Zoom digunakan untuk diskusi dan menjelaskan materi. Dengan google classroom dosen dapat menyampaikan materi berupa PPT dan video sesuai topik, tugas individu dan kelompok. Materi dan tugas bisa di download oleh mahasiswa untuk dipelajari dan digunakan menyelesaikan tugas. Hasil penyelesaian tugas individu/kelompok di unggah di google classroom sesuai waktu yang ditentukan, kemudian dipresentasikan pada pertemuan berikutnya dengan menggunakan Zoom. Hal ini sesuai penelitian sebelumnya dilakukan (Istyadji, 2018) pembelajaran berbasis masalah berbantuan diskusi daring membuktikan terdapat perbedaan hasil belajar kognitif yang signifikan pada kelas eksperemen dan kontrol.

Menurut (Rostyanta et al., 2020) Pembelajaran daring dengan google classroom secara tidak langsung membangun kebiasaan siswa untuk belajar mandiri, mulai dari cara mendisiplinkan diri dalam mengatur waktu untuk belajar, mengerjakan semua tugas atau latihan yang diberikan dosen, mengerjakan tugas dan belajar sesuai dengan ketentuan. Kegiatan- kegiatan tersebut merupakan indikator dari sikap dan tindakan bertanggung jawab.Pembelajaran dengan google classroom yang memanfaatkan fitur-fitur yang ada google classroom sebagai media dapat meningkatkan tanggung jawab dan disiplin, ini diwujudkan dari upaya-upaya yang dilakukan siswa untuk beradaptasi dalam penggunaan. Diperkuat hasil penelitian (Rostyanta et al., 2020) membuktikan bahwaPembelajaran daring dengan Google Class room terintegrasi video interaktif dapat meningkatkan sikap dan Tindakan bertanggung jawab.

Menurut (Fitriyani, Febriyeni, \& Kamsi, 2020) aplikasi zoom cloud meeting, seakan-akan menjadi kelas baru dalam proses pembelajaran. Serta aplikasi ini pun menjadi solusi agar pembelajaran disekolah atau perguruan tinggi berjalan dengan semestinya" hasil penelitian(Monica \& Fitriawati, 2020) menunjukkan bahwa pembelajaran yang dilakukan secara online menggunakan aplikasi Zoom di ARS University saat adanya virus covid-19 adalah effektif. Hal ini sesuai pendapat (Fitriyani et al., 2020) bahwa penggunaan aplikasi zoom pada pembelajaran online sebagai solusi dimasa pandemi karena aplikasi zoom yang fleksibel dan sangat mudah digunakan dan didapat. Berdasarkan penelitian sebelumnya terbukti pembelajaran daring dengan aplikasi zoom sebagai media efektif untuk mendukung proses pembelajaran agar optimal.

Menurut (Surur \& Tartila, 2019)Model PBL adalah pembelajaran yang menyajikan masalah kontekstual sehingga dapat merangsang siswa untuk dapat mengembangkan kemampuan menyelesaikan masalah, berpikir kritis, dan membangun pengetahuan baru. Melalui PBL siswa dilatih untuk memecahkan masalah yang ada dan bekerja dalam kelompok sehingga siswa lebih aktif dalam mengontruksi pembelajarannya. Langkah-langkan pembelajaran berbasis masalah dalam penelitian ini ini sesuai teori (Indrahadi \& Junaidi, 2017) adalah:1) mengorientasi peserta didik pada masalah,2) mengorganisasi peserta didik untuk belajar, 3) penyelidikan atas masalah, 4)pengembangan dan menyajikan hasil investigasi,5) menganalisis dan mengevaluasi proses pemecahan masalah.Langkahlangkah yang tersebut kemudia disesuaikan dengan media yang digunakan dalam pembelajran berbasis masalah sistem daring dengan berbantuan googlke clasroom dan Zoom. Adapun langkahlangkah pembelajaran berbasis masalah sistem daring berbantuan google classroom dan zoom dalam penelitian ini adalah sebagai berikut 


\section{Efektor, Volume 8 Issue 2,2021, Pages 122 - 131 \\ Sulastri Rini Ridrayani}

Tabel 1 langkah-Langkah Pembelajaran Berbasis Masalah Sistem Daring

\begin{tabular}{|c|c|c|c|}
\hline Tahap & Indikator Kerja & Kegiatan Dosen & Media Pembelajaran \\
\hline 1 & Orientasi Masalah & $\begin{array}{l}\text { Mngunggah materi di google class room ( PPT } \\
\text { dan Vidio), Mb tugas kelompok berbasis } \\
\text { masalah dan b capaian pembelajaran ) }\end{array}$ & Google Clsroom \\
\hline 2 & $\begin{array}{l}\text { Mengorganisasipeserta } \\
\text { didik untuk meneliti }\end{array}$ & $\begin{array}{l}\text { Mahasiwa mendowload materi, vidio, tugas } \\
\text { kelompok di google clssroom }\end{array}$ & Google Classrom \\
\hline 3 & $\begin{array}{l}\text { Penyelidikan atas } \\
\text { masalah }\end{array}$ & $\begin{array}{l}\text { Mahasiswa secara kelompok mengerjakan } \\
\text { tugas sesuai petunjuk dan menggungah tugas } \\
\text { pada google classroom }\end{array}$ & Google Classroom \\
\hline 4 & $\begin{array}{l}\text { mengembangkan dan } \\
\text { menyajikan karya }\end{array}$ & $\begin{array}{l}\text { Mahasiswa mempresentasikan tugas yang } \\
\text { diberikan secara kelompok melalui zoom } \\
\text { Dosen memberikan penilaian presentasi penyaji } \\
\text { secara virtual }\end{array}$ & Zoom \\
\hline 5 & $\begin{array}{l}\text { mengevaluasi proses } \\
\text { pemecahan masalah. }\end{array}$ & $\begin{array}{l}\text { Evaluasi materi yang disajikan oleh kelompok } \\
\text { penyaji melalui diskusi kelas virtual. } \\
\text { Dosen dan mahasiswa menyimpulkan materi }\end{array}$ & Zoom \\
\hline
\end{tabular}

Menurut (Saputri, Nurlela, \& Patras, 2020) hasil belajar adalah hasil dari suatu kegiatan yang telah dikerjakan, diciptakan, yang diperoleh dengan kerja keras, baik secara individu maupun kelompok setelah mengalami proses pembelajaran. Sementara (Nurdyansah \& Toyiba, 2018) hasil belajar adalahhasil yang telah dicapai oleh seseorang setelah melakukan kegiatan belajar yangmeliputi aspek kognitif, afektif, dan psikomotorik yang dapat dinyatakan dengansimbol-simbol, angka, huruf, maupun kalimat yang dapat mencerminkan kualitaskegiatan individu dalam proses tertentu. Sedangan (Wihartanti, 2017) hasil belajar adalah kemampuan keterampilan, sikap dan keterampilan yang diperoleh siswa setelah ia menerima perlakuan yang diberikan oleh guru sehingga dapat mengkonstruksikan pengetahuan itu dalam kehidupan sehari-hari. Berdasarkan beberapa pengertian tersbut maka hasil belajar pada penelitian ini adalah nilai yang di peroleh mahasiswa melalu tes tulis subyektif untuk mengetahui kompetensi sikap, pengetahuan dan ketrampilan pada materi penerapan penawaran dan permintaan yang di ujikan setelah selesai penerapan pembelajaran menggunakan pembelajaran berbasis masalah sistem daring berbantuan google classroom kombinasi zoom.

Tanggung jawab merupakan atribut psikologi yang tidak dapat dilihat namun bentuk atau wujudnya dapat dimanifestasikan dalam bentuk, tingkah laku dan kebiasaan. Suatu perilaku maupun kebiasaan tidak dapat muncul dan berubah begitu saja, memerlukan suatu proses dan waktu yang cukup lama untuk dapat merubahnya menjadi lebih baik atau bahkan menghilangkannya sama sekali(A'an Aisyah , Eko Nusantoro, 2014). Menurut (Dewi, 2016)Individu yang bertanggung jawab adalah individu yang dapat memenuhi tugas belajar dan memenuhi kebutuhan dirinya sendiri, serta dapat memenuhi tanggung jawab terhadap lingkungan sekitarnya dengan baik. Berdasarkan pengertian tersbut dapat disimpulkan tanggung jawab adalah tingkah laku dan kebiasaan individu dapat memenuhi tugas belajar, kebutuhan diri sendiri dan memenuhi kewajiban terhadap lingkungan sekitarnya.

Indikator tanggung jawab menurut (Kurniawati, 2014) kemandirian siswa dalam belajar, kesadran siswa dalam belajar, dan kemampuan siswa dalam menjalankan tugas dan kewajiban. Sedangkan (Rostyanta et al., 2020) menjabarkan kreteria tanggung jawab beserta indikatornya sebagai berikut :

Tabel 2 Kreteria Tanggung Jawab Dan Indikator

\begin{tabular}{cl}
\hline Kreteria Bertanggung Jawab & \multicolumn{2}{c}{ Indikator } \\
\hline Do The Work (melakukan Pekerjaan) & $\begin{array}{l}\text { Menyelesaikan tuigas dalam jangka waktu tertentu dan } \\
\text { menyelesaikan tugas yang telah menjadi tanggun }\end{array}$
\end{tabular}




\section{Efektor, Volume 8 Issue 2,2021, Pages 122 - 131 \\ Sulastri Rini Ridrayani}

Oey The Rules ( mematuhi peraturan)

Pay attention (memperhatikan)

Learn or study ( belajar atau mempelajari)

Try or make an effort

( mencoba atau berusaha)

Responsibility as something that given or taken jawabnya

Mengikuti serta patuh pada aturan yang telah ditetapkan Memperhatikan informasi yang diberikan serta memperhatikan konsekuensi dari segala sesuatu yang telah menjadi tanggung jawabnya

Memperoleh atau menggali pengetahuan baik secara individu maupun dari lingkungan sekitar

Berupaya dan mencoba berbagai macam strategi untuk mampu menyelesaikan tugas yang dimilikinya tepat waktu agar mencapai hasil yang berkualitas Membuat Membuat pilihan dan kualitas pekerjaan sesuai tanggung jawabnya

Sumber : (Rostyanta et al., 2020)

Berdasarkan teori di atas maka indikator tanggung jawab dalam penelitian ini adalah belajar mandiri, kesadaran siswa dalam belajar, melakukan pekerjaan, mematuhi peraturan, memperhatikan, belajar mempelajari dan mencoba. Sesuai teori (Rostyanta et al., 2020)(Kurniawati, 2014)

\section{METODE PENELITIAN}

Penelitian ini merupakan penelitian kuantitatif komparatif untuk mengetahui pengaruh pembelajaran berbasis masalah sistem daring berbantuan google classroom kombinasi zoom terhadap hasil belajar Ekonomi Mikro 1 dan tanggung jawab pada mahasisa Program Studi Pendidikan Ekonomi. Populasi dalam penelitian ini adalah mahasiswa Program Studi Pendidikan Ekonomi Universitas Bhinneka PGRI sedang menempuh mata kuliah Ekonoi Mikro 1 sebanyak 84 mahasiswa yang terbagi menjadi 2 kelas. Pada kelas pertama merupakan kelas eksperimen memperoleh perlakukan pembelajaran berbasis masalah sistem daring berbantuan google classroom kombinasi zoom, sedangkan kelas ke dua merupakan kelas kontrol menggunakan pembelajaran daring google classroom

Metode pengumpulan data menggunakan Tes tertulis subyektif sebayak lima soal digunakan untuk mengumpulkan data hasilbelajar. Metode Angket/kuesioner untuk mengumpulkan data tanggung jawab. Instrumen kuesioner menggunakan pertanyaan tertutup yaitu pertanyaan sudah tersedia jawaban, responden tingal memilihnya. Jawaban terdiridari lima option Sangat Setuju - skor 5, Setuju = skor 4, Cukup setuju $=$ Skor 3, Tidak Setuju $=$ skor 2, dan Sangat tdak Setuju $=$ skor 1.Jumlah pertanyaan sebanyak 16 item, maka skor terendah 16 dan tertinggi 80.Untuk menentukan nilai akhir.dengan rumus: Nilai = jumlah skor perolehan/jumlah sekor maksimum X 100. Hasil nilai kemudian diklasifikasi dengan ketentuan pada tabel 3. Analisis data menggunakan statistik Uji One Way Manova

Tabel 3 Klasifikasi Nilai Hasil Belajar dan Tanggung Jawab

\begin{tabular}{ccc}
\hline No & Nilai & Klasifikasi Nilai \\
\cline { 1 - 1 } 2 & $84-100$ & Sangat Baik \\
3 & $68-83$ & Baik \\
4 & $52-67$ & Cukup baik \\
5 & $36-51$ & Kurang baik \\
& $20-35$ & Sangat Tidak baik \\
\hline
\end{tabular}

Sumber data: data yang diolah

\section{HASIL DAN PEMBAHASAN}

Langkah pertama analisis data adalah melakukan uji validitas dan reliabilitas instrument. Ketentuan uji validitas menggunakan Pearson Correlation suatu instrument valid apabila signifikan korelasi < 0,05 .Hasil analisis data uji validitas instrument tanggung jawab sebanyak 16 item semua valid, terbukti Signifikan pearson correlation 16 item sebesar $0,00<0,05$. Sedangkan ketentuan uji reabilitas, suatu 


\section{Efektor, Volume 8 Issue 2,2021, Pages 122 - 131 \\ Sulastri Rini Ridrayani}

instrument dikatakan reliabel apabila nilai Cronbach's Alpha> 0,6, Hasil analisis data menunjukkan besar Cronbach's Alpha 0,924 >0,6

Tabel 4 Mean Hasil Belajar dan Tanggung Jawab

Descriptive Statistics

\begin{tabular}{clccc}
\hline & Pembelajaran & Mean & Std. Deviation & $\mathrm{N}$ \\
\hline \multirow{3}{*}{ Hasil_belajar } & Google clasroom kombinasi Zoom & 76.90 & 6.355 & 42 \\
& Google clasroom & 62.45 & 4.950 & 42 \\
& $\quad$ Total & 69.68 & 9.214 & 84 \\
\multirow{2}{*}{ Tanggung_jawab } & Google clasroom kombinasi Zoom & 71.21 & 7.980 & 42 \\
& Google clasroom & 70.62 & 7.827 & 42 \\
& $\quad$ Total & 70.92 & 7.862 & 84 \\
\hline
\end{tabular}

Sumber Data: Hasil Analisis SPSS

Pada tebel 4 menujukan bahwa nilai rata-rata hasil belajar pembelajaran berbasis masalah sistem daring kombinasi google classroom dan zoom sebesar 76,90 pada klasifikasi nilai baik sedangkan nilai rata-rata hasil belajar menggunakan google classroom sebesar 62.45 pada klasifikasi cukup baik. Hal ini dapat diartikan bahwa nilai rata-rata hasil belajar pembelajaran berbasis masalah sistem daring berbantuan google classroom kombinasi zoom lebih tinggi daripada nilai hasil belajar menggunakan pembelajaran google classroom. Nilai rata-rata tanggung jawab pembelajaran berbasis masalah sistem daring berbantuan google classroom kombinasi zoom sebesar 71.21 pada klasifikasi baik sedangkan nilai tanggung jawab menggunakan pembelajaran google classroom sebesar 70,62 pada klasifikasi baik. Hal ini dapat diartikan bahwa nilai rata-rata tanggung jawab antara pembelajaran berbasis masalah sistem daring berbantuan google clasroon kombinasi zoom disbanding dengan kelas yang menggunakan pembelajaran google calsroom hampir sama pada klasifikasi baik.

Tabel 5 Uji Normalitas

Tests of Normality

\begin{tabular}{|c|c|c|c|c|c|c|c|}
\hline & \multirow{2}{*}{ Pembelajaran } & \multicolumn{3}{|c|}{ Kolmogorov-Smirnov ${ }^{a}$} & \multicolumn{3}{|c|}{ Shapiro-Wilk } \\
\hline & & Statistic & df & Sig. & Statistic & df & Sig. \\
\hline \multirow[t]{2}{*}{ Hasil_belajar } & $\begin{array}{l}\text { Google clasroom } \\
\text { kombinasi Zoom }\end{array}$ & .153 & 42 & .015 & .914 & 42 & .004 \\
\hline & Google clasroom & .120 & 42 & .135 & .929 & 42 & .012 \\
\hline \multirow[t]{2}{*}{ Tanggung_jawab } & $\begin{array}{l}\text { Google clasroom } \\
\text { kombinasi Zoom }\end{array}$ & .135 & 42 & .051 & .905 & 42 & .002 \\
\hline & Google clasroom & .143 & 42 & .030 & .913 & 42 & .004 \\
\hline
\end{tabular}

a. Lilliefors Significance Correction

Sumber Data. Hasil analisis SPSS

Uji asumsi normalitas digunakan untuk menguji apakah residual yang dihasilkan dalam manova berdistribusi normal atau tidak.Peryarat pada uji manova data harus berdistribusi normal.Uji normalitas menggunakan Kolmogorov-Smirnov, dengan ketentuan apabila nilai signifikanpada KolmogorovSmirnov> 0,05 maka data memiliki distribusi normal. Hasil analisis data pada tabel 5 menunjukan besar Signifikan Kolmogorov-Smirnov pada kelas menggunakan goolee classroom kombinasi zoom : hasil belajar 0,15>0,05 dan tanggung jawab 1,35>0,05 sedangkan yang menggunakan google classroom $\mathrm{t}$ signifikan Kolmogorov-Smirnov hasil belajar 0,51 >0,05 dan tanggung jawab 0,30. $>0,05$. Dengan demikian dapat disimpulkan baha semua data hasil belajar dan tanggung jawab berdistribusi normal.

Uji asumsi homogenitas digunakan untuk menguji apakah residual yg dihasilkan dalam manova memiliki ragam yang homogen atau tidak.Dalam manova diharapkan residual memiliki ragam yg homogen.Untuk mengetahui homoginitas matrik varian dan covarian menggunakan Box's M Tes. Ketentuannya apabila nilai pengujian memperoleh signifikan $>0,05$ maka matrik varian covarian antar 


\section{Efektor, Volume 8 Issue 2,2021, Pages 122 - 131 \\ Sulastri Rini Ridrayani}

kelompok homogin. Hasil analisis data pada tabel 6 menunjukansignifikan pada tabel Box'MTes sebesar $0,473>0,05$, dengan demikian dapat disimpulkan bahwa data antar variabel adalah hmogin.

Tabel 6 Uji Asumsi Homoginitas secara Bersama

Box's Test of Equality of Covariance Matrices ${ }^{a}$

\begin{tabular}{cc}
\hline Box's M & 2.582 \\
\hline $\mathrm{F}$ & .838 \\
$\mathrm{df1}$ & 3 \\
$\mathrm{df2}$ & 1210320.000 \\
Sig. & .473 \\
\hline
\end{tabular}

Tests the null hypothesis that the observed covariance matrices of the dependent variables are equal across groups.
a. Design: Intercept + Pembelajaran

Sumber data : Hasil SPSS

Untuk mengetahui homoginitas varian secara univarian menggunakan tabel levene's test.Ketentuan pengujian apabila Signifikan pada levene's test > 0,05 maka variantiap kelas homogin. Dari hasil analisis data pada tabel 7 menunjukan signifikan levene's test hasilbelajar 0.141>0,05 dan Tanggung Jawab $0.97>0,05$, maka dapat disimpulkan varian data pada masing-masing variabel hasil belajar dan tanggung jawab baik di kelas yang menggunakan pembelajaran berbasis masalah sistem daring berbantuan google classroom maupun pada kelas yang menggunakan pembelajaran daring google clasroom adalah homogin

Tabel 7 Homoginitas Varian Univarian

Levene's Test of Equality of Error Variances ${ }^{a}$

\begin{tabular}{ccccc}
\hline & $F$ & df1 & df2 & Sig. \\
\hline Hasil_belajar & 2.205 & 1 & 82 & .141 \\
Tanggung_jawab & .001 & 1 & 82 & .972 \\
\hline
\end{tabular}

Tests the null hypothesis that the error variance of the dependent variable is equal across groups.

a. Design: Intercept + Pembelajaran

Sumber data: Hasil Analisis SPSS

Uji Multivariate digunakan untuk menguji $\mathrm{HO}$ : tidak ada perbedaan yang signifikan secara simultan pembelajaran berbasis masalah sistem daring berbantuan google classroom kombinasi zoom terhadap hasil belajar Ekonmi Mikro 1 dan tanggung jawab pada mahasisa Program Studi Pendidikan Ekonomi. Ketentuan ada perbedaan secara simultan apabila nilai $F$ Wilks' Lambda meiliki signifikansi $<0,05$

Tabel 8 Uji Multivariate

\begin{tabular}{|c|c|c|c|c|c|c|c|}
\hline \multicolumn{8}{|c|}{ Multivariate Tests ${ }^{\mathrm{a}}$} \\
\hline Effect & & Value & $\mathrm{F}$ & Hypothesis df & Error df & Sig. & $\begin{array}{l}\text { Partial Eta } \\
\text { Squared }\end{array}$ \\
\hline \multirow{4}{*}{ Intercept } & Pillai's Trace & .996 & $9205.317^{b}$ & 2.000 & 81.000 & .000 & .996 \\
\hline & Wilks' Lambda & .004 & $9205.317^{b}$ & 2.000 & 81.000 & .000 & .996 \\
\hline & Hotelling's Trace & 227.292 & $9205.317^{b}$ & 2.000 & 81.000 & .000 & .996 \\
\hline & Roy's Largest Root & 227.292 & $9205.317^{b}$ & 2.000 & 81.000 & .000 & .996 \\
\hline \multirow{4}{*}{ Pembelajaran } & Pillai's Trace & .623 & $66.789^{b}$ & 2.000 & 81.000 & .000 & .623 \\
\hline & Wilks' Lambda & .377 & $66.789^{b}$ & 2.000 & 81.000 & .000 & .623 \\
\hline & Hotelling's Trace & 1.649 & $66.789^{b}$ & 2.000 & 81.000 & .000 & .623 \\
\hline & Roy's Largest Root & 1.649 & $66.789^{b}$ & 2.000 & 81.000 & .000 & .623 \\
\hline
\end{tabular}




\title{
Efektor, Volume 8 Issue 2,2021, Pages 122 - 131 \\ Sulastri Rini Ridrayani
}

\author{
a. Design: Intercept + Pembelajaran \\ b. Exact statistic \\ Sumber Data: Hasil analisi SPSS
}

Berdasarkan hasil analisis data pada tabel 8 menunjukan besar nilai $\mathrm{F}$ Wilks' Lambda 66,78 signifikan $0,000<0,05$, berarti Ho ditolak Ha diterima, kesimpulannya Ada perbedaan yang signifikan pembelajara berbasis masalah sistem daring berbantuan google classroom kombinasi zoom terhadap hasil belajar Ekonomi Mikro 1 dan tanggung jawab pada mahasiswa Program Studi Pendidikan Ekonomi. Temuan ini membuktikan teori yang dikrmukakan (Fitriyani, Febriyeni, \& Kamsi, 2020)bahwa aplikasi zoom cloud meeting, seakan-akan menjadi kelas baru dalam proses pembelajaran. Serta aplikasi ini pun menjadi solusi agar pembelajaran disekolah atau perguruan tinggi berjalan dengan semestinya.Hasil penelitian ini membuktikan temuan penelitianyang dilakukan (Rostyanta et al., 2020) bahwaPembelajaran daring dengan Google Class room terintegrasi video interaktif dapat meningkatkan sikap dan Tindakan bertanggung jawab. Selain ituhasilpenelitian ini juga membuktikan temuanpenelitian yang dilakukan Julita tahun 2018 bahwa terdapat peningkatan ketuntasan hasil belajar peserta didik dan peningkatan keaktivan peserta didik dan guru dalam proses pembelajaran berbasis masalah. Dengan demikian dapat disimpulkan bahwa ada pengaruh pembelajaran berbasis masalah sistem daring berbantuan google classroom kombinasi zoom terhadap hasil belajar dan Tanggung Jawab. Temuan ini juga membuktikan bahwa pembelajaran berbasis masalah sistem daring berbatuan googgle classroom kombinasi zoom lebih efektif dibanding hanya menggunakan googlee clasroom.

Tabel 9 Uji Univariate

Tests of Between-Subjects Effects

\begin{tabular}{|ll|r|r|r|r|r|r|}
\hline Source & Dependent Variable & $\begin{array}{c}\text { Type III Sum } \\
\text { of Squares }\end{array}$ & df & Mean Square & $\mathrm{F}$ & Sig. & $\begin{array}{r}\text { Partial Eta } \\
\text { Squared }\end{array}$ \\
\hline Corrected & Hasil_belajar & $4386.298^{\mathrm{a}}$ & 1 & 4386.298 & 135.215 & .000 & .622 \\
Model & Tanggung_jawab & $7.440^{\mathrm{b}}$ & 1 & 7.440 & .119 & .731 & .001 \\
Intercept & Hasil_belajar & 407828.679 & 1 & 407828.679 & 12572.050 & .000 & .994 \\
Pembelajar & Tanggung_jawab & 422450.583 & 1 & 422450.583 & 6761.880 & .000 & .988 \\
an & Tanil_belajar & 4386.298 & 1 & 4386.298 & 135.215 & .000 & .622 \\
Error & Hasil_belajar & 2660.024 & 82 & 32.439 & .119 & .731 & .001 \\
& Tanggung_jawab & 5122.976 & 82 & 62.475 & & & \\
Total & Hasil_belajar & 414875.000 & 84 & & & & \\
Corrected & Tanggung_jawab & 427581.000 & 84 & & & & \\
Total & Tanil_belajar & 7046.321 & 83 & & & & \\
\hline
\end{tabular}

a. $\mathrm{R}$ Squared $=.622$ (Adjusted $\mathrm{R}$ Squared $=.618$ )

b. R Squared $=.001$ (Adjusted R Squared $=-.011)$

Sumber Data : Hasil Analisis SPSS

Test of Beteen-Subjects Effcts digunakan untuk pengujian model secara univariate. Ketentuan apabila signifikanuji $\mathrm{F}<0,05 \mathrm{HO}$ di tolak dan Ha diterima. Hasil analisis data pada tabel 9 menunjukan hasil belajar nilai $\mathrm{F}$ hitung $=132.215$ dengan signifikan $0,00<0,05$, berarti $\mathrm{HO}$ di tolak dan $\mathrm{Ha}$ di terima: kesimpulan Ada perbedaan yang sifnifikan pembelajaran berbasis masalah sistem daring berbatuan google classroom kombinasi zoom terhadap hasil belajar.Hasil penelitian ini penelitian sebelumnya dilakukan (Istyadji, 2018) pembelajaran berbasis masalah berbantuan diskusi daring membuktikan terdapat perbedaan hasil belajar kognitif yang signifikan pada kelas eksperemen dan kontrol. Selain itu juga mendukung penelitian (Santika, Parwati, \& Divayana, 2020)membuktikan pembelajaran berbasis 


\section{Efektor, Volume 8 Issue 2,2021, Pages 122 - 131 \\ Sulastri Rini Ridrayani}

masalah dalam setting pembelajaran daring terdapat perbedaan prestasi belajar matematika antara siswa yang belajar dengan model pembelajaran berbasis masalah dan model pembelajaran langsung.hasil temuan ini juga membuktikan pembebelajaran berbasis masalah sistem daring berbantuan google classroom kombinasi zoom lebih efektif dalam meningkatkan hasil belajar di banding hanya menggunakkan google classroom.

Pada tabel 9 menunjukan nilai $F$ hitung tanggung jawab sebesar 0.119 signifikan $0,731>0.05$, berate Ho di terima dan Ha ditolak. Dapat disimpulkan tidak ada perbedaan pembelajaran berbasis masalah sistim daring berbantuan google classroom kombinasi zoom terhadap tanggung jawab Pada mahasiswa Program Studi Pendidikann Ekonomi. Hal ini dapat di artikan bahwa mahasiswa sudah memiliki tanggung jawab yang baik terhadap tugas yang diberikan baik menggunakan pembelajaran berbasis masalah sistem daring google classroom kombinasi zoom maupun pembelajaran hanya menggunakan google classroom saja.Hal ini sesuai teori (Rostyanta et al., 2020) Pembelajaran daring dengan google classroom secara tidak langsung membangun kebiasaan siswa untuk belajar mandiri, mulai dari cara mendisiplinkan diri dalam mengatur waktu untuk belajar, mengerjakan semua tugas atau latihan yang diberikan dosen, mengerjakan tugas dan belajar sesuai dengan ketentuan.

\section{SIMPULAN}

Berdasarkan hasil analisis Multivariate membuktikan bahwa ada perbedaan yang signifikan pembelajaran berbasis masalah sistem daring berbantan google classroom kombinasi zoom terhadap hasil belajar Ekonomi Mikro dan tanggung jawab pada mahasisa Program Studi Pendidikan Ekonomi.Temuan ini dapat diartikan pembelajaran berbasis masalah sistem daring berbatuan google classroom kombinasi zoom lebih efektif dibanding hanya menggunakan daring google classroom terhadap hasil belajar dan tanggung jawab. Analisis data univariate membuktikan ada perbedaan signifikan pembelajaranberbasis masalah sistem daring berbatuan google classroom kombinasi zoom terhadap hasil belajar Ekonomi Mikro 1 pada mahasiswa program studi Pendidikan ekonomi. Temuan ini dapat dijelaskan bahwa pembelajaran berbasis masalah sistem daring menggunakan gogle classroom kombinasi zoom lebih efekti dalam meningkatkan hasil belajar disbanding pembelajaran google classroom.Hasil analisis Univariate juga membuktikan tidak ada perbedaan pembelajaranberbasis masalah sistem daring berbatuan google classroom kombinasi zoom terhadap Tanggung Jawab. Temuan ini dapat dijelaskan bahwa mahasiswa sudah memiliki tanggung jawab yang biak terhadap tugas yang diberikan dalam pembelajaran baik pada kelas yang menggunakan pembelajaran berbasis masalah sistem daring berbantuan google classroom kombinasi zoom maupun kelas yang hanya menggunakan google classroom.

\section{DAFTAR RUJUKAN}

A'an Aisyah, Eko Nusantoro, K. K. (2014). Meningkatkan Tanggung Jawab Belajar Melalui Layanan Konten. Indonesian Journal of Guidance and Counseling: Theory and Application, 3(3), 44-50. Retrieved from journal.unnes.ac.id/sju/index.php/jbk

Dewi, F. P. (2016). Tingkat Tanggung Jawab Belajar Siswa Kelas Viii Smp Negeri 13 Yogyakarta Tahun Ajaran 2015/2016 Dan Implikasinya Terhadap Usulan Topik-Topik Bimbingan Belajar (pp. 1-100). Retrieved from repository.usd.ac.id/6902/2/111114002_full.pdf

Fitriyani, Febriyeni, M. D., \& Kamsi, N. (2020). Penggunaan Aplikasi Zoom Cloud Meeting Pada Proses pembelajaran online Sebagai Solusi Dimasa Pandemi Covid. Edification, 3(1), 23-34.

Fiyanti, O., Rahmawati, N. K., \& Wulandari, A. (2020). Perbedaan Hasil Belajar Matematika Peserta Didik dengan Pembelajaran E-Learning Berbantuan Aplikasi Zoom dan Google Classroom. Prosiding Seminar Nasional Pendidikan STKIP Kusuma Negara II, Abstrak Pe, 132-138. Retrieved from scholar.google.co.id/citations?user=UOy4fdIAAAAJ\&hl=id

Indrahadi, D., Junaidi, Chong, T. T., Chinese, M., Hmong, W., Classifi, T. I. I., ... Bruce, 2011. (2017). Upaya Meningkatkan Kemampuan Peserta Didik Berpikir Kritis Melalui Penerapan Srategi Pembelajaran Berbasis Masalah Pada Pembelajaran Sosiologi Kelas Xi Ips 2 Sma Negeri 1 


\section{Efektor, Volume 8 Issue 2,2021, Pages 122 - 131 \\ Sulastri Rini Ridrayani}

Pariaman. Jurnal Sosius . Jurnal Od Sociology Research and Education, 4(1), 22-30.

Istyadji, M. (2018). Implementasi Problem Based Learning Berbantuan Diskusi Daring terhadap

Kemampuan Memecahkan masalah dan hasil Belajar Kimia Pada Materi Larutan Penyangga.

Journal of Chemistry And Education, 1(3), 237-244. Retrieved from

http://jtam.ulm.ac.id/index.php/jcae/article/view/105

Julita, J. (2018). Peningkatan Kemampuan Pemecahan Dan Hasil Belajar Matematika Melalui Problem

Based-Learning. Mosharafa: Jurnal Pendidikan Matematika, 7(1), 143-154.

https://doi.org/10.31980/mosharafa.v7i1.350

Kurniawati, R. (2014). Penanaman Karakter Tanggung Jawab Siswa Pada Pelaksanaan Ulangan

Harian Dalam Mata Pelajaran PKn Studi Kasus: Siswa Kelas VII B MTs Muhammadiyah 07 Klego

Boyolali Tahun Ajaran 2013/2014) Naskah (pp. 1-12). Retrieved from

eprints.ums.ac.id/29729/9/NASKAH_PUBLIKASI.pdf

Monica, J., \& Fitriawati, D. (2020). Efektivitas Penggunaan Aplikasi Zoom Sebagai Media Pembelajaran

Online Pada Mahasiswa Saat Pandemi Covid-19. Jurnal Communio : Jurnal Jurusan IImu

Komunikasi, 9(2), 1630-1640. https://doi.org/10.35508/jikom.v9i2.2416

Nurdyansah, \& Toyiba, F. (2018). Pengaruh Strategi Pembelajaran Aktif Terhadap Hasil Belajar Pada Madrasah Ibtidaiyah. Retrieved from http://eprints.umsida.ac.id/1610/

Rostyanta, I., Sutiadiningsih, A., Bahar, A., \& Miranti, M. G. (2020). Pengaruh Pembelajaran Dengan

Google Classroom Diintegrasikan Video Interaktif Terhadap Keterampilan Berfikir Kritis Dan

Bertanggung Jawab. JURNAL TATA BOGA (JTB), 9(1), 142-153. Retrieved from

https://ejournal.unesa.ac.id/index.php/jurnal-tata-boga/\%

Rusydiyah, E. F., Neville, A., Gledhill, A., Johnston, D., Zhang, H., Xu, J. J., ... Dutta, D. (2019).

Tekonologi Pembelajaran Implementasi Pembelajaran Era 4.0. Retrieved from

http://dx.doi.org/10.1016/j.cirp.2016.06.001\%0Ahttp://dx.doi.org/10.1016/j.powtec.2016.12.055\%0

Ahttps://doi.org/10.1016/j.ijfatigue.2019.02.006\%0Ahttps://doi.org/10.1016/j.matlet.2019.04.024\%0

Ahttps://doi.org/10.1016/j.matlet.2019.127252\%0Ahttp://dx.doi.o

Santika, I. W. D., Parwati, N. N., \& Divayana, D. (2020). Pengaruh Model Pembelajaran Berbasis Masalah Dalam Setting Pembelajaran Daring Terhadap Prestasi Belajar Matematika dan Kemampuan Pemecahan Masalah .... Jurnal Teknologi Pembelajaran Indonesia, X, 105-117.

Retrieved from https://semnaslppm.ump.ac.id/index.php/semnaslppm/article/view/145

Saputri, R., Nurlela, N., \& Patras, Y. E. (2020). Pengaruh Berpikir Kritis Terhadap Hasil Belajar Matematika. JPPGuseda | Jurnal Pendidikan \& Pengajaran Guru Sekolah Dasar, 3(1), 38-41. https://doi.org/10.33751/jppguseda.v3i1.2013

Suhada, I., Kurniati, T., Pramadi, A., Listiawati, M., Biologi, P. P., Gunung, S., \& Bandung, D. (2020). Pembelajaran Daring Berbasis Google Classroom Mahasiswa Pendidikan Biologi Pada Masa Wabah Covid-19. Digital Library UIN Sunan Gunung Jati, 2019, 1-9. Retrieved from http://digilib.uinsgd.ac.id/30584/

Surur, M., \& Tartila. (2019). Pengaruh Problem Based Learning Dan Motivasi Berprestasi Terhadap Kemampuan Pemecahan Masalah. Indonesian Journal of Learning Education and Counseling, 1(2), 169-176. https://doi.org/10.31960/ijolec.v1i2.96

Wihartanti, L. V. (2017). Pengaruh Model Pembelajaran Jigsaw Terhadap Hasil Belajar Studi Masyarakat Indonesia Mahasiswa. Pendidikan Ekonomi UM Metro, 5(1), 84-94. Retrieved from http://www.fkip.ummetro.ac.id/journal/index.php/ekonomi/article/view/849 